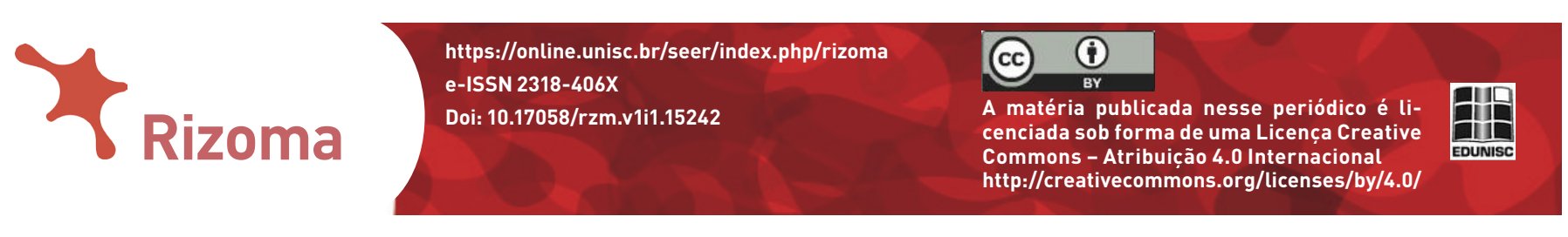

\title{
Resenha
}

\section{Os Engenheiros do Caos}

EMPOLI, Giuliano da. Os engenheiros do Caos - como as Fake Fagner Torres de França ${ }^{1}$ Lilian Carla Muneiro² News, as teorias da conspiração e os algoritmos estão sendo utilizados para disseminar ódio, medo e influenciar eleições. Tradução Arnaldo Bloch. $1^{\text {a }}$ ed. São Paulo: Vestígio, 2019

No Brasil e no mundo, autores como Esther Solano (2018), Ana Kiffer, Gabriel Giorgi (2019) e Jacques Rancière (2015), apenas para citar alguns, debruçaram-se sobre o tema do ódio na política. Principalmente por causa de seu caráter enigmático de revolta conservadora. Mas uma das interpretações mais penetrantes acerca do fenômeno vem da tinta do escritor franco-italiano Giuliano Da Empoli (2019), em seu ensaio mais recente Os engenheiros do Caos. À primeira vista, a obra pode parecer mais uma teoria da conspiração, na qual um punhado de gente, por meio de estratagemas sofisticados, tenta dominar e manipular as gentes em prol de seus interesses. Um olhar mais aproximado desfaz a impressão. O problema das conspirações é que elas podem existir.

O livro, com 190 páginas e uma leitura fluida a partir de uma escritura bem engendrada, que poderia muito bem passar por ficção, é dividido em introdução, seis capítulos e uma conclusão. Seu objetivo principal é compreender como um ódio disperso, muitas vezes sem objeto, pode ser capturado e canalizado para atender objetivos políticos a partir da utilização da mais alta tecnologia algorítmica de mineração e análise de dados que disponibilizamos diária e voluntariamente nas redes sociais. Esse material é a argamassa potente capaz de erguer verdadeiros edifícios de ódio, do Brasil aos EUA, passando por Polônia e Hungria.

Os engenheiros do caos não são seres etéreos. Alguns são bem conhecidos no mundo político e fazem questão de apresentar-se como são: engenheiros do caos. São eles: Steve Bannon, Arthur Finkelstein, Gianroberto e Davide Casallegio (pai e filho), Milo Yannopoulos,

1 Jornalista, mestre e doutor em Ciências Sociais pela UFRN.

2 Professora associada do Departamento de Comunicação Social da UFRN. Doutora em Comunicação e Semiótica (PUC/ 


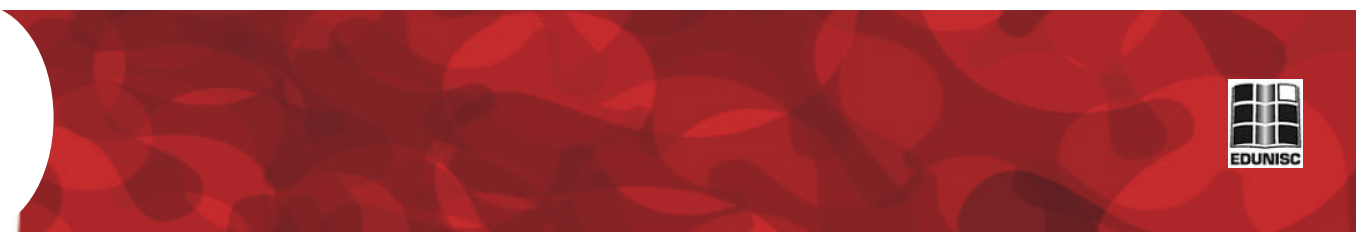

Dominic Cummings e Andrew Breitbart. Talvez você não associe o nome à pessoa, mas certamente já ouviu falar em Brexit, Cambridge Analytica, Movimento 5 Estrelas, Gabinete do Ódio, Viktor Orbán, Donald Trump, Jair Bolsonaro. Todos estes fenômenos políticomidiáticos têm um dedo (ou vários) destas figuras.

A introdução do livro dá o tom da obra com leveza e elegância é pegar e não largar. Parte de um relato do jovem Goethe observando, da sacada de um hotel em Roma, o carnaval que agitava a multidão em 19 de fevereiro de 1787. No carnaval as coisas se transformam, as hierarquias se diluem temporariamente, os valores são subvertidos, o nobre vira plebeu e vice-versa, as regras sociais são provisoriamente suspensas, nada parece ser o que é. Qualquer coisa pode ser e/ou não ser. Só que a festa carnavalesca começa e termina. Deixa a euforia como lembrança. Esta é a sensação alimentada em movimentos populares. Como afirma o autor,

\footnotetext{
Onde quer que seja, na Europa ou em outros continentes, o crescimento dos populismos tomou a forma de uma dança frenética que atropela e vira ao avesso todas as regras estabelecidas. Os defeitos e vícios dos líderes populistas se transformam, aos olhos dos eleitores, em qualidades (p. 17).
}

E viramos todos foliões, antagônicos. A política torna-se questão de engajamento e não de ideias discutidas racionalmente em esfera pública. Não há como passar em meio ao carnaval sem engajar-se.

O capítulo um, $O$ Vale do Silício do Populismo, introduz o leitor a uma das personalidades mais controversas da atualidade. Steve Bannon é filho da classe trabalhadora americana, e cheio de ressentimento contra elites econômicas e intelectuais do mundo, a quem se refere como traidores do povo. Mas ao invés de desperdiçar sua raiva em discussões de botequim, decidiu investir naquilo que o filósofo alemão Peter Sloterdijk (2012) chama de banco de cólera (veremos isso mais à frente), criando estratégias para ajudar a eleger pessoas afinadas com seus ideais.

Quais são seus ideais? Difícil dizer. Ele acredita que os liberais americanos construíram uma hegemonia globalista a partir de um marxismo cultural que é preciso substituir por uma internacional nacionalista (uma contradição em termos). A ideia é retomar o controle popular sobre o governo, elegendo pessoas como Trump ou Bolsonaro, que se dizem preocupadas com os destinos de seu país e de seu povo. Tudo isso, claro, parece delírio. Mas lembre-se que se trata de engajamento, de contágio, da canalização do ódio para um projeto redentor de poder. Não estamos no mundo da lógica analítica. Parece carnaval, e antes fosse. Teria data de início e término. 


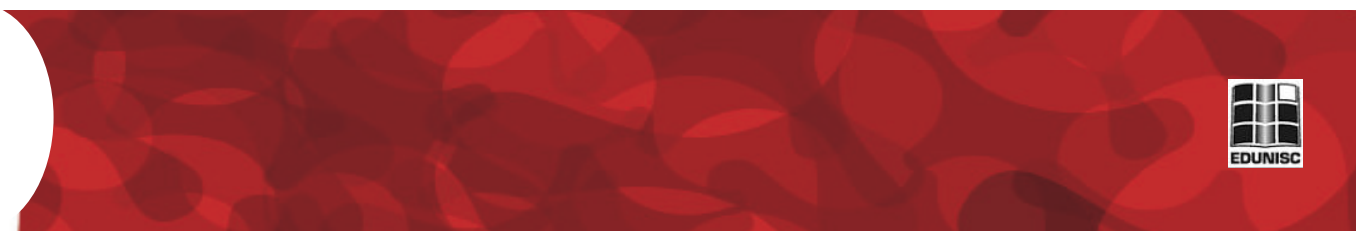

Estaríamos avisados e não imersos tentando entender o que se passa, e que, aparentemente, não tem pé nem cabeça. Acontece na Itália, nos EUA ou no Brasil. E Bannon passou por todos estes lugares.

Em todos os casos, estamos falando de um tecnopopulismo pós-ideológico fundado em algoritmos. Bannon é um homem do povo, que gostaria de devolver-lhe o poder usurpado pela elite mundial (lembremos do Take back control, slogan do Brexit). Mas como? Interpretando e interferindo em nossos desejos e sentimentos de forma objetiva, a partir dos dados que produzimos via internet posteriormente transformados em estatísticas. Para isso não é necessária a criação de um Partido Político. Em seu lugar entra o Partido Empresa, ou Partido Algoritmo. Basta seguir a direção na qual caminha a opinião pública - monitorada em tempo real. Por isso assistimos estarrecidos a governantes que falam coisas totalmente diferentes dependendo do dia, do humor do público, ou da plateia para a qual se dirigem.

É como Partido Empresa que se organiza, por exemplo, o Movimento 5 Estrelas (M5S) na Itália, umas das principais forças da direita populista no país. Seus deputados eleitos respondem aos números e ao dono do partido (que não é político, mas administrador da empresa), Davide Casaleggio, herdeiro único do partido após a morte do pai. Essa história intrigante sobre a aliança política entre um gestor em marketing digital (Gianroberto Casaleggio, pai) e um comediante desbocado e performático (Bepe Grillo), encontra-se no capítulo dois, A Netflix da política.

Waldo conquista o planeta é o título do terceiro capítulo. Waldo é um ursinho azul virtual e canastrão que ficou conhecido mundialmente a partir de 2013 ao protagonizar um dos episódios da série britânica Black Mirror. Seu combustível é o ódio, a paranoia e a frustração com o mundo e consigo próprio - Waldo é comandado por um ser humano frustrado e ressentido. Aqui já podemos retomar Sloterdijk. Em seu livro Ira e Tempo (2012), o filósofo alemão reconstrói a história política da raiva. Durante os séculos, algumas instituições se responsabilizaram por administrá-la. Primeiro, a Igreja Católica. Em seguida, já no século XIX, os partidos políticos de esquerda. Hoje, ninguém mais gerencia a cólera, que se manifesta de forma cada vez mais desorganizada e caótica. Mas Empoli tem uma percepção diferente.

(...) anos depois da publicação do ensaio de Sloterdijk, já está comprovado que as forças da ira se reorganizaram e expressam-se no centro da galáxia dos novos populismos, que, do Leste Europeu aos EUA, passando pela Itália, a Áustria e os países escandinavos, dominam cada dia um pouco mais a cena política de seus respectivo países (p. 72). 


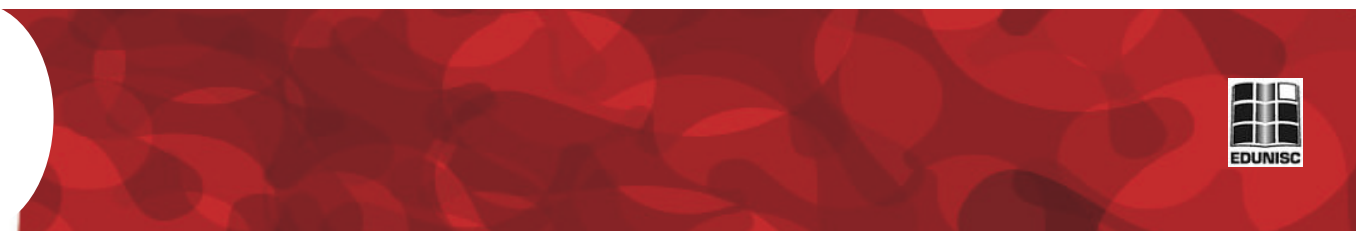

A principal missão dos partidos empresas é canalizar o ódio contra os representantes da elite à esquerda ou à direita. Alinhadas à democracia liberal, nenhuma destas forças tem condições de dar uma resposta eficaz aos problemas de um mundo de consumidores cuja temporalidade é sempre a instantaneidade. No Partido Empresa, o tempo histórico da política não tem vez. Os partidos empresas esvaziam o centro político e se colocam como anti-políticos, mas em verdade trabalham para unir os desejos justamente pelos extremos do ódio. Haverá sempre uma mensagem de ódio para quem necessita de uma justificativa.

A identificação não se faz pelo reconhecimento do outro, mas com o líder. O mundo divide-se entre "nós" e "eles". Isso faz a união do populismo, embora algumas mensagens possam soar contraditórias (como, por exemplo, um apelo democrático por uma ditadura militar). Do MBL, no Brasil, aos Coletes Amarelos, na França, vários movimentos estão contemplados neste capítulo. No livro, o autor demonstra certo conhecimento sobre nossa cultura, política e costumes. Aliás, já escreveu um ensaio sobre o país: Hedonismo e medo. O futuro brasileiro do mundo (2007).

O capítulo quatro, Troll, o chefe, apresenta uma história no mínimo inusitada. Em 2005, o ainda desconhecido Steve Bannon deixa Hollywood para alojar-se em Hong Kong. Lá, participa do lançamento da empresa Internet Gaming Entertainment. A empresa explora a popularidade de um famoso jogo de vídeo game chamado World Of Warcraft, que conta com milhões de aficcionados pelo mundo. A Internet Gaming Entertainment contrata milhares de jovens chineses para jogar o game dia e noite e acumular troféus, que depois podem ser vendidos (em dinheiro real) a jogadores ocidentais preguiçosos.

Mas para alguns gamers que fazem do jogo sua razão de viver, essa prática nada mais é que uma trapaça que corrompe a honra dos guerreiros digitais. Contudo, os jogadores que fazem do $W O W$ seu ganha pão desejam continuar seu trabalho, e inicia-se uma guerra virtual extremamente violenta de ambas as partes. Bannon percebe aí as forças escondidas nos subterrâneos da internet, capazes de sérias ameaças, denúncias, difamações. É o cerne da ideia das campanhas negativas. Ao voltar aos EUA, Bannon procura imediatamente aliança com o jornalista Andrew Breitbart, responsável pelo mais conhecido site de extrema-direita nos EUA, Breitbart News. A ideia é mobilizar as correntes invisíveis e poderosas de ódio que alimentam milhões de indivíduos à margem da sociedade.

Ao invés dos gamers, Bannon desloca o alvo da cólera para o establishment político e midiático. Qualquer semelhança com o Brasil de 2020 não é mera coincidência. Bannon agencia os gamers para sua cruzada contra o marxismo cultural, mas faltam ainda duas coisas: 


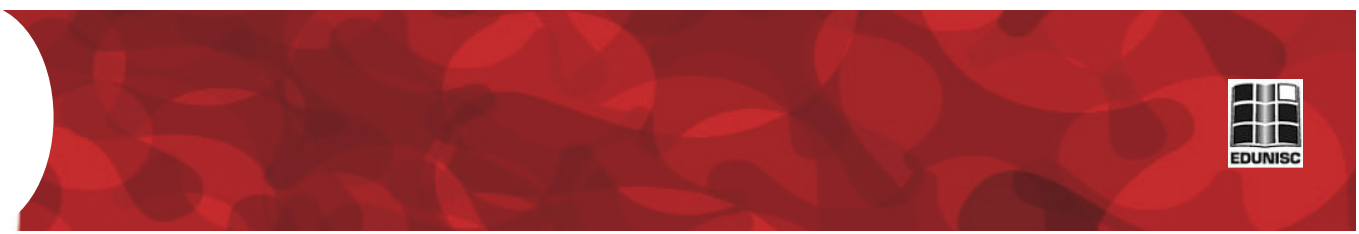

o rosto e o discurso. $\mathrm{O}$ rosto, claro, parece ter nascido para isso: o milionário apresentador de TV Donald Trump. O discurso, por sua vez, não pode ser nada menos que apocalíptico: seu mundo corre perigo, a poderosa máquina do politicamente correto e de censores democratas quer tirar tudo o que você mais preza, a liberdade de expressão, o anonimato, os valores da pátria e da família, sua liberdade, seus direitos civis, sua propriedade. A tropa digital montada por Bannon não tem limites. Sua única política é a de terra arrasada: insultos, perseguições, xingamentos, difamações, mentiras. O troll chefe, como o leitor já deve ter adivinhado, é hoje presidente dos EUA.

O capítulo cinco, intitulado Um estranho casal em Budapeste, parte de uma história trágica. Era janeiro de 2015 quando dois homens armados invadiram a sede do jornal satírico Charlie Hebdo, em Paris, e mataram 12 pessoas, deixando cinco feridos. No dia seguinte, dois milhões de franceses e chefes de estado de toda Europa saem às ruas em marcha para demonstrar união e coragem e ao mesmo tempo repudiar os atos terroristas. Entre os chefes de Estado estava Viktor Orbán, da Hungria.

Orbán percebe ali (com ajuda de um misterioso e discreto engenheiro do caos, chamado Arthur Finkelstein) uma raiva acumulada possível de ser drenada para seus propósitos de perpetuação no poder. Mesmo que à época a Hungria tivesse apenas 1,4\% de imigrantes no total de sua população, sendo uma minoria deles de origem mulçumana, seu discurso é incisivo contra a imigração, o Islã, e a favor do nacionalismo e dos valores da cultura húngara. $\mathrm{O}$ discurso, embora sem lastro na realidade, atingiu em cheio uma camada de eleitores capaz de mantê-lo no poder ainda hoje.

O sexto capítulo, Os fisicos e os dados, trata de um tema fundamental. O misterioso Finkelstein foi um dos inventores do que o autor chama de microtargeting, ou seja, mirar a mensagem apenas para as pessoas certas, as influenciáveis, ao invés de distribui-la a torto e a direito. Isso pode fazer enorme diferença na contagem final de votos. Como no caso de Trump, que venceu no Estado do Wisconsin por uma margem apertada de 11 mil votos (para uma população de 6 milhões de pessoas). A estratégia é mirar tanto nos indecisos para votarem quanto convencer aqueles que pendem para o adversário a não saírem de casa no dia da votação (já que, nos EUA, o voto é facultativo).

Seria isso a realização da física social, como inicialmente ficou conhecida a sociologia? Os físicos são, agora, mais importantes que os cientistas políticos para compreender a realidade e empreender uma reengenharia social? "Esta profusão de dados - e os poderosos interesses econômicos que ela representa - está na raiz do novo papel do físico na política" (EMPOLI, 2019, p. 144). Estaríamos, assim, rumando para uma administração cientifica da política? Difícil dizer 
agora, mas esse é o objetivo dos engenheiros do caos. Distorcer, produzir e conduzir novas realidades.

Esse é justamente o mote da conclusão, chamada $A$ era $d a$ política quântica. A física de Newton apresentava um mundo mecânico ordenado, mais ou menos racional, controlável, no qual a uma ação correspondia uma reação. A física quântica desfaz essa ideia e revela mais esta ferida narcísica. "Com a política quântica, a realidade objetiva não existe. Cada coisa se define provisoriamente, em relação a uma outra, e, sobretudo, cada observador determina sua própria realidade" (EMPOLI, 2019, p. 174-5), mesmo que para isso seja preciso negar a realidade mais evidente. Chama-se a isto de negacionismo. Cada pessoa vive em sua própria bolha, constituindo uma incapacidade atávica de se colocar no lugar do outro.

No fundo, não se trata de ter uma opinião sobre determinado fato, mas as bolhas colaboram para que todos tenham seus próprios fatos e construam sua própria realidade. Nas palavras do autor,

\begin{abstract}
A política quântica é plena de paradoxos: bilionários se tornam os porta-estandartes da cólera dos desvalidos; os responsáveis por decisões públicas fazem da ignorância uma bandeira; ministros contestam os dados de sua própria administração. O direito de se contradizer e ir embora, que Baudelaire invocava para os artistas, virou, para os novos políticos, o direito de se contradizer e permanecer, sustentando tudo e seu contrário, numa sucessão de tweets e de transmissões ao vivo no Facebook que vai construindo, tijolo após tijolo, uma realidade paralela para cada um dos seguidores (EMPOLI, 2019, p. 176).
\end{abstract}

Em suma, o campo progressista tem muito a fazer e aprender se quiser reinventar as formas e os conteúdos políticos na era da política quântica.

\title{
REFERÊNCIAS
}

EMPOLI, Giuliano da. Os engenheiros do Caos - como as Fake News, as teorias da conspiração e os algoritmos estão sendo utilizados para disseminar ódio, medo e influenciar eleições. Tradução Arnaldo Bloch. 1a ed. São Paulo: Vestígio, 2019.

EMPOLI, Giuliano da. Hedonismo e medo. O futuro brasileiro do mundo. Porto Alegre: Sulina, 2007. 
KIFFER, Ana; GIORGI, Gabriel. Ódio político e políticas do ódio: lutas gestos e escritas do presente. Rio de Janeiro: Bazar do tempo, 2019. 136 p. (Coleção Por que Política?, v. 5).

RANCIÈRE, Jacques. O ódio à democracia. São Paulo: Boitempo editorial, 2015.

SLOTERDIJK, Peter. Ira e tempo. Ensaio político-psicológico. Tradução Marco Casanova. São Paulo: Estação Liberdade, 2012.

SOLANO, Esther (ORG). O ódio como política. A reinvenção das direitas no Brasil. São Paulo: Boitempo editorial, 2018. 